\begin{tabular}{lcl}
\hline Bentham open & The Open Nanomedicine Journal \\
CrossMark & Content list available at: www.benthamopen.com/TONMJ/ \\
DOI: $10.2174 / 1875933501805010016$ & The Open \\
Nanomedicine \\
lournal
\end{tabular}

REVIEW ARTICLE

\title{
Zinc Oxide Nanoparticles: Therapeutic Benefits and Toxicological Hazards
}

\author{
Said Said Elshama ${ }^{1,2}$, Metwally E. Abdallah ${ }^{1}$ and Rehab I. Abdel-Karim ${ }^{1, *}$ \\ ${ }^{1}$ Forensic Medicine and Clinical Toxicology Department, Faculty of Medicine, Suez Canal University, Ismailia, Egypt. \\ ${ }^{2}$ College of Medicine, Taif University, Taif, Saudi Arabia.
}

\begin{abstract}
Despite the widespread application of zinc oxide nanoparticles in biomedicine, their use is still a controversial issue. Zinc oxide nanoparticles were reported to have therapeutic benefits. However, they were reported to have toxicological hazards as well. Several studies reported the antibacterial, anticancer, antioxidant, and immunomodulatory effects of zinc oxide nanoparticles. Additionally, zinc oxide nanoparticles were used in sunscreens. Furthermore, the ability to use zinc oxide nanoparticles as an adjuvant treatment to alleviate the toxic effects of chemotherapeutic drugs has been reported. However, zinc oxide nanoparticles were shown to induce toxic effects in different body organs and systems. The affected organs included liver, spleen, kidney, stomach, pancreas, heart and lung. In addition, zinc oxide nanoparticles were reported to adversely affect the neurological system, lymphatic system, hematological indices, sex hormones levels, and fetal development. The toxic effects of zinc oxide nanoparticles were based on their concentration, their dose, the route of their administration, and the time of exposure to those particles. Thus, it is crucial to assess their efficacy and safety to determine their toxicological risks and therapeutic benefits.
\end{abstract}

Keywords: Zinc oxide, Nanoparticles, Benefits, Hazards, Antibacterial, Anticancer.

\section{BACKGROUND}

Nanoparticles may be natural or synthetic. Synthetic nanoparticles are classified into several types; such as metal nanoparticles (e.x. gold and silver nanoparticles), metal oxide nanoparticles (e.x. zinc oxide), carbon nanoparticles, and quantum dots (e.x. cadmium selenide). Synthetic nanoparticles have physicochemical features and special reactivity, which are attributed to their small size, and to their high surface area in comparison to their larger counterparts of the same material. In synthetic nanoparticles, the proportion of atoms on the surface is much larger than the proportion of atoms in the interior of the particle. These factors give synthetic nanoparticles a higher surface reactivity than their counterparts of the same material [1].

Zinc is a nutritional supplement and food additive. The melted and oxidized zinc at a high temperature can generate zinc oxide nanoparticles that affect the growth of many bacteria such as Staphylococcus, Streptococcus, and E. coli [2]. Currently, there are widespread applications of zinc oxide nanoparticles in medicine because of their antibacterial effect. They are also used in several industries such as paints, pigments, dyes, electronics, cosmetics and personal care products. Consequently, humans are more exposed to zinc oxide nanoparticles via various routes such as dermal penetration, inhalational, oral and intravenous routes. In the last few years, the use of zinc oxide nanoparticles became controversial. Although zinc oxide nanoparticles can pass easily through the cell membrane and interact with cellular macromolecules leading to therapeutic effects on some organs, they were found to exert oxidative stress causing cytotoxic effects on other organs [3].

\footnotetext{
* Address correspondence to this author at the Forensic Medicine \& Clinical Toxicology Department, Faculty of Medicine, Suez Canal University, Ismailia, Egypt; Tel: 00201007344788; E-mail: rehabnegm@yahoo.com
} 


\subsection{Therapeutic Benefits of Zinc Oxide Nanoparticles}

Nanomedicine is considered a new trend in the world. It is concerned with the biomedical application of nanotechnology in the early diagnosis and treatment of diseases. In recent years, many types of research tried to use the unique properties of nanoparticles; especially zinc oxide nanoparticles in the treatment of some diseases [4]. Zinc oxide nanoparticles have bioavailability, biocompatibility, and high solubility. Therefore, they can mimic the biomolecules' activity, and can localize in many body systems wherein biomolecules can regulate the cellular cycle, and maintain cellular homoeostasis [5]. In the last decades, chemotherapy, radiation therapy, and surgery were the primary choices for cancer treatment, but they had many adverse effects due to their non-selective effects on the cells; as they might affect normal cells as well. Therefore, searching for another substitute therapy that has the ability to both destroy cancer cells and overcome the various adverse effects of the traditional cancer therapy has become mandatory [6].

Zinc oxide nanoparticles were approved by Food and Drug Administration (FDA) as a new and potent anticancer therapy [7]. Zinc oxide nanoparticles can produce selective cytotoxicity towards cancer cells via the induction of disequilibrium of zinc-dependent protein activity, in addition to the production of reactive oxygen species [8]. Rasmussen et al. [9] emphasized the ability of zinc oxide nanoparticles to kill cancer cells through the induction of oxidative stress in the cancerous cells. Furthermore, zinc is involved in all cellular protecting processes against cancer through the activation of DNA repair, and hence preventing both apoptosis and cancer cell growth [10].

Zinc channels create a balance between cell survival and cell death via controlling the free and intracellular zinc movements [11]. Zinc also plays an important role to maintain the tumor suppressor gene p53 activity that regulates apoptosis activity [12]. Moreover, zinc can also help in the activation of the caspase-6 enzyme which is responsible for apoptosis. Therefore, zinc deficiency causes DNA damage and p53 disruption, resulting in the loss of DNA integrity and the potential for increased cancer risk. Hence, zinc oxide nanoparticles are considered potent therapy for many cancers [13].

Many published articles have mentioned that zinc oxide nanoparticles had more than 30 times selective cytotoxicity towards cancer cells compared to healthy cells, and that they could kill cancer cells selectively in vitro and vivo via inferring the selective localization [14 - 16]. Zinc oxide nanoparticles were characterized by their enhanced permeation, and by their retention inside the tumor cells. The small size and the surface properties of zinc oxide nanoparticles enabled them to diffuse easily through the blood vessels towards the tumor cells, and to be localized inside these cells specifically, and hence act on them [17]. Moreover, as zinc oxide nanoparticles show positive charges in the physiological conditions; such as in tissue fluid or in blood, while the cancerous cells have negatively charged phospholipids on their outer membranes, an electrostatic attraction occurs between zinc oxide nanoparticles and the cancerous cells $[18,19]$. Bisht and Rayamajhi [20] reported that zinc oxide nanoparticles have shown anti-proliferative effects, and that zinc nanoparticles succeeded to treat a human gastric adenocarcinoma cell line, resulting in a significant inhibition of cellular proliferation. Therefore, Bisht and Rayamajhi supported the use of zinc oxide nanoparticles as a promising anticancer agent with fewer side effects in comparison to the traditional anticancer therapy.

Badkoobeh et al. [21] suggested that zinc oxide nanoparticles could be used as a potent antioxidant, and as an effective adjuvant treatment to chemotherapeutic drugs that cause reproductive dysfunction in males. This was based upon the ability of zinc oxide nanoparticles to increase the therapeutic efficacy of doxorubicin, and to reduce doxorubicin gonado-toxic properties. Furthermore, several studies revealed the ability of zinc to ameliorate the oxidative stress and glutathione depletion. Other studies emphasized the ability of zinc to enhance the reproductive function, and reported that zinc was found in high levels in the male reproductive system and in the seminal fluid. Therefore, zinc is thought to play an important role in spermatogenesis process [22]. In the same context, Dawei et al. [23] indicated that zinc oxide nanoparticles had the ability to increase antioxidant enzymes levels, and to decrease malondialdehyde (MDA) level. Therefore, zinc oxide nanoparticles could protect the cell membrane integrity against oxidative stress damage. On the contrary, Sharma et al. [24] reported that sub-acute oral exposure of zinc oxide nanoparticles could induce oxidative stress, DNA damage, and apoptosis in the liver.

Atef et al. [25] showed that low doses of zinc oxide nanoparticles had cytoprotective effects. These particles could improve antioxidant activity, and decrease the levels of free radicals resulting from Aflatoxin B1. Aflatoxin B1 induced detrimental effects on humans as well as on animals eating Aflatoxins contaminated feedstuff. Aflatoxins-induced toxic effects included teratogenic, carcinogenic, mutagenic and immunosuppressive effects. Studies have shown a direct correlation between dietary aflatoxins intake in humans and liver cancer [26]. Therefore, according to Atef et al. [25], zinc oxide nanoparticles could protect the hepatic cells from the damaging effect of Aflatoxin B1 through scavenging 
free radicals [25].

Zinc oxide nanoparticles affected the growth of both gram positive and gram negative bacteria; so, they could be considered as potent antibacterial agents. The antibacterial effect of zinc oxide nanoparticles is due to the high sensitivity of the lipid bilayer of bacteria to the reactive oxygen species produced by these nanoparticles [27 - 29]. Moreover, zinc oxide nanoparticles could also be considered as antifungal agents; because they could completely stop the growth of some types of fungi when administered at high concentrations. However, recent studies show that the impact of zinc oxide nanoparticles on some organisms is not yet sufficiently understood despite their widespread use in biomedicine [29].

In the field of cosmetics, zinc oxide nanoparticles powder is widely used in sunscreens and ointments [30]. Zinc oxide nanoparticles are considered as ultraviolet blockers and semiconductor agents because they could absorb and scatter the visible ultraviolet rays. The photocatalytic activity of zinc oxide nanoparticles increases with decreasing their sizes [31]. Numerous studies on healthy human skin suggested that zinc oxide nanoparticles don't penetrate beyond the stratum corneum when they are used in sunscreens [32].

Zinc oxide nanoparticles are widely used in dietary supplements. They were found to produce an immunomodulatory effect. Roy et al. reported that zinc oxide nanoparticles increased antigen-specific immune reactions in mice. They enhanced antigen-specific antibodies production in serum, especially immunoglobulin $\mathrm{E}$ (IgE) and immunoglobulin $\mathrm{G}(\mathrm{IgG})$, and they also could enhance the functionality of $\mathrm{T}$ cells. It was also detected that zinc oxide nanoparticles had an adjuvant effect toward Th2 response; increasing the production and activation of cytokines [33].

\subsection{Toxicological Hazards of Zinc Oxide Nanoparticles}

In recent years, a number of studies have shown the possibility of using zinc oxide nanoparticles as therapeutic agents and as gene carriers. At the same time, many published research studies showed the toxic effects of zinc oxide nanoparticles on some specific organs and cell lines. These toxic effects were attributed to the high solubility of the particles, resulting in cytotoxicity, oxidative stress, and mitochondrial dysfunction. Therefore, an urgent necessity exists to evaluate both the toxicological hazards and the therapeutic benefits for the use of zinc oxide nanoparticles in medicine. Furthermore, it is important to determine if their toxicity is reversible, and if this toxicity depends on the concentration and the time of exposure to the particles [34].

Inhalation of zinc oxide nanoparticles induced inflammation and fibrosis in the alveolar and tracheobronchial tissues depending on the size and solubility of the particles. Acidic lung fluid resulted in the dissolution of zinc oxide nanoparticles, and consequently increased their concentration leading to pulmonary toxicity [35]. Furthermore, zinc oxide nanoparticles induced cytotoxicity in human lung epithelial cells via inducing oxidative stress in a concentrationdependent manner, resulting in DNA damage and apoptosis [36].

Intra-peritoneal injection of zinc oxide nanoparticles was found to cause neurotoxic effects in the form of attenuation of the learning ability and memory according to the study of Han et al. [37]. Elshama et al. [38] found that the prolonged use of zinc oxide nanoparticles via intra-peritoneal route induced histopathological and ultrastructural changes in the brains and spinal cords of rats, depending on the dose, and based on reactive oxygen species generation.

Moreover, Li et al. [39] reported that both intraperitoneal and oral administration of zinc oxide nanoparticles led to systemic distribution and toxic accumulation of the particles in the liver, spleen, kidney, and lung; which were the target organs where the toxic manifestations of zinc oxide nanoparticle have appeared. In male rats, zinc oxide nanoparticles elevated liver enzymes, and led to harmful effects on the body metabolism [40]. In the same context, Soheili et al. [41] reported that the administration of zinc oxide nanoparticles increased significantly all liver enzymes (e.g. aspartate transaminase "AST", alanine transaminase "ALT", alkaline phosphatase "ALP” and lactate dehydrogenase "LDH”) in a dose-dependent manner. Furthermore, the authors reported an increase in the blood glucose level, suggesting the defective effects of zinc oxide nanoparticles on the pancreatic cells. Administration of zinc oxide nanoparticles was also found to induce severe anemia and significant histopathological changes on the livers and hearts of rats. The histopathological changes were in the form of hyaline degeneration of the cardiac muscle and focal hemorrhages associated with hepatic apoptosis. Esmaeilloua et al. [42] demonstrated that zinc oxide nanoparticles had severe oxidative toxic effects on kidney, lung, and liver. The effects were dependent on the physicochemical properties of nanoparticles such as the specific surface area and the nanoparticle size.

In addition, Ko et al. [43] reported that zinc oxide nanoparticles adversely altered the hematological indices such as 
hemoglobin, hematocrit, mean corpuscular volume, mean corpuscular hemoglobin, mean corpuscular hemoglobin concentration, platelets, and white blood cells (total and differential). They also reported histopathological changes in the spleen, stomach, and pancreas associated with zinc oxide nanoparticles administration. In the same context, Seoka $e t$ al. [44] showed that oral intake of high dose zinc oxide nanoparticles led to pancreatitis and anemia.

Kim et al. [45] showed that the oral administration of different doses of $100 \mathrm{~nm}$ zinc oxide nanoparticles with different surface charges and for a prolonged period induced significant histopathological changes, such as squamous and glandular cell hyperplasia in the stomach, acinar cell apoptosis in the pancreas, retinal atrophy, and suppurative inflammation in the prostate. They also detected disturbances in most hematological indices, and in other biochemical parameters such as blood urea nitrogen, blood glucose and calcium, albumin, and alkaline phosphatase. The previously reported toxic effects were observed at doses greater than $125 \mathrm{mg} / \mathrm{kg}$, while the No Observed Adverse Effect Level (NOAEL) was $31.25 \mathrm{mg} / \mathrm{kg}$.

Sub-chronic use of zinc oxide nanoparticles was found to induce toxic manifestations in the lymphatic system and in the blood cell count depending on the administered dose. The nanoparticles induced a decrease in the total blood cell count (white blood cells, red blood cells, and platelets), a disturbance in the differential white blood cell count, and produced histopathological and ultrastructural changes in thymus, spleen and lymph nodes in rats [46].

Reza et al. [47] conducted a study to investigate the deleterious effects of treating rats with different doses of zinc oxide nanoparticles on Thyroid Stimulating Hormone (TSH), Follicular Stimulating Hormone (FSH) and Luteinizing Hormone (LH) levels, and on cholesterol level in the blood. The authors detected a decrease in FSH level and an increase in TSH level; however, they found an increase in the cholesterol level. The induced effects on rats were associated with the administration of high doses only.

Although available data about the effects of zinc oxide nanoparticles on reproduction and on fetal development are not enough so far, Hong et al. [48] reported that the administration of repeated oral doses of zinc oxide nanoparticles in rats during pregnancy and for short periods of time -not exceeding 15 days- led to maternal and developmental toxicity.

\section{CONCLUSION}

Widespread application of zinc oxide nanoparticles in biomedicine attracts wide attention to assess their therapeutic benefits compared to their expected toxicological hazards. Zinc oxide nanoparticles have many therapeutic effects, where they may have antibacterial, anticancer, immunomodulatory, sunscreen and antioxidant effects, or they may be used as an adjuvant treatment to chemotherapeutic drugs to alleviate their toxic effects. Systemic distribution of zinc oxide nanoparticles may lead to toxic manifestations in different body organs and systems, based on their concentration, the administered dose, the route of administration, and on the time of exposure to them. Therefore, Zinc oxide nanoparticles can affect liver, spleen, kidney, stomach, pancreas, heart, lung, neurological system, lymphatic system and hematological indices. They can also affect sex hormones levels and fetal development.

\section{RECOMMENDATION}

Further studies need to be done in the future to verify the therapeutic efficacy of zinc oxide nanoparticles, along with the assessment of their toxicological hazards in order to determine the risk benefit ratio of their use in medicine.

\section{CONSENT FOR PUBLICATION}

Not applicable.

\section{CONFLICT OF INTEREST}

The authors declare no conflict of interest, financial or otherwise.

\section{ACKNOWLDEGEMENTS}

Declared none.

\section{REFERENCES}

[1] Handy RD, von der Kammer F, Lead JR, Hassellöv M, Owen R, Crane M. The ecotoxicology and chemistry of manufactured nanoparticles. Ecotoxicology 2008; 17(4): 287-314.

[http://dx.doi.org/10.1007/s10646-008-0199-8] [PMID: 18351458] 
[2] Kao YY, Chen YC, Cheng TJ, Chiung YM, Liu PS. Zinc oxide nanoparticles interfere with zinc ion homeostasis to cause cytotoxicity. Toxicol Sci 2012; 125(2): 462-72. [http://dx.doi.org/10.1093/toxsci/kfr319] [PMID: 22112499]

[3] Espanani HR, Fazilati M, Sadeghi L, Yousefi BV, Bakhshiani S, Amraie E. Investigation the zinc oxide nanoparticle's effect on sex hormones and cholesterol in rat. Int Res J Biol Sci 2013; 2(8): 54-8.

[4] McNeil SE. Nanoparticle therapeutics: a personal perspective. Wiley Interdiscip Rev Nanomed Nanobiotechnol 2009; 1(3): $264-71$. [http://dx.doi.org/10.1002/wnan.6] [PMID: 20049796]

[5] Vizirianakis IS. Nanomedicine and personalized medicine toward the application of pharmacotyping in clinical practice to improve drugdelivery outcomes. Nanomedicine (Lond) 2011; 7(1): 11-7. [http://dx.doi.org/10.1016/j.nano.2010.11.002] [PMID: 21094279]

[6] Gowda R, Jones NR, Banerjee S, Robertson GP. Use of nanotechnology to develop multi-drug inhibitors for cancer therapy. J Nanomed Nanotechnol 2013; 4(6): 184-8. [http://dx.doi.org/10.4172/2157-7439.1000184] [PMID: 25013742]

[7] Shen C, James SA, de Jonge MD, Turney TW, Wright PF, Feltis BN. Relating cytotoxicity, zinc ions, and reactive oxygen in ZnO nanoparticle-exposed human immune cells. Toxicol Sci 2013; 136(1): 120-30. [http://dx.doi.org/10.1093/toxsci/kft187] [PMID: 23997113]

[8] Vinardell MP, Mitjans M. Antitumor activities of metal oxide nanoparticles. Nanomaterials (Basel) 2015; 5(2): 1004-21 [http://dx.doi.org/10.3390/nano5021004] [PMID: 28347048]

[9] Rasmussen JW, Martinez E, Louka P, Wingett DG. Zinc oxide nanoparticles for selective destruction of tumor cells and potential for drug delivery applications. Expert Opin Drug Deliv 2010; 7(9): 1063-77. [http://dx.doi.org/10.1517/17425247.2010.502560] [PMID: 20716019]

[10] Ho E. Zinc deficiency, DNA damage and cancer risk. J Nutr Biochem 2004; 15(10): 572-8. [http://dx.doi.org/10.1016/j.jnutbio.2004.07.005] [PMID: 15542347]

[11] Dhawan DK, Chadha VD. Zinc: A promising agent in dietary chemoprevention of cancer. Indian J Med Res 2010; 132: 676-82. [PMID: 21245614]

[12] $\mathrm{Ng} \mathrm{KW}$, Khoo SP, Heng BC, et al. The role of the tumor suppressor p53 pathway in the cellular DNA damage response to zinc oxide nanoparticles. Biomaterials 2011; 32(32): 8218-25. [http://dx.doi.org/10.1016/j.biomaterials.2011.07.036] [PMID: 21807406]

[13] Costello LC, Franklin RB, Feng P, Tan M, Bagasra O. Zinc and prostate cancer: a critical scientific, medical, and public interest issue (United States). Cancer Causes Control 2005; 16(8): 901-15. [http://dx.doi.org/10.1007/s10552-005-2367-y] [PMID: 16132800]

[14] Taccola L, Raffa V, Riggio C, et al. Zinc oxide nanoparticles as selective killers of proliferating cells. Int J Nanomedicine 2011; 6: 1129-40. [PMID: 21698081]

[15] Thurber A, Wingett DG, Rasmussen JW, et al. Improving the selective cancer killing ability of ZnO nanoparticles using Fe doping. Nanotoxicology 2012; 6(4): 440-52. [http://dx.doi.org/10.3109/17435390.2011.587031] [PMID: 21635174]

[16] Ostrovsky S, Kazimirsky G, Gedanken A, Brodie C. Selective cytotoxic effect of ZnO nanoparticles on glioma cells. Nano Res 2009; 2(11): 882-90. [http://dx.doi.org/10.1007/s12274-009-9089-5]

[17] Akhtar MJ, Ahamed M, Kumar S, Khan MM, Ahmad J, Alrokayan SA. Zinc oxide nanoparticles selectively induce apoptosis in human cancer cells through reactive oxygen species. Int J Nanomedicine 2012; 7: 845-57. [PMID: 22393286]

[18] Thurber A, Wingett DG, Rasmussen JW, et al. Improving the selective cancer killing ability of ZnO nanoparticles using Fe doping. Nanotoxicology 2012; 6(4): 440-52. [http://dx.doi.org/10.3109/17435390.2011.587031] [PMID: 21635174]

[19] Degen A, Kosec M. Effect of pH and impurities on the surface charge of zinc oxide in aqueous solution. J Eur Ceram Soc 2000; 20(6): 667-73. [http://dx.doi.org/10.1016/S0955-2219(99)00203-4]

[20] Bisht G, Rayamajhi S. ZnO Nanoparticles: A Promising Anticancer Agent. Nanobiomedicine (Rij) 2016 ; $3: 9$. [http://dx.doi.org/10.5772/63437] [PMID: 29942384]

[21] Badkoobeh P, Parivar K, Kalantar SM, Hosseini SD, Salabat A. Effect of nano-zinc oxide on doxorubicin- induced oxidative stress and sperm disorders in adult male Wistar rats. Iran J Reprod Med 2013; 11(5): 355-64. [PMID: 24639766]

[22] Zago MP, Oteiza PI. The antioxidant properties of zinc: interactions with iron and antioxidants. Free Radic Biol Med 2001; $31(2)$ : 266-74. [http://dx.doi.org/10.1016/S0891-5849(01)00583-4] [PMID: 11440839]

[23] Dawei AI, Zhisheng W, Angu Z. Protective effects of Nano-ZnO on the primary culture mice intestinal epithelial cells in in vitro against 
oxidative injury. Int J Nanotechnol 2009; 3: 1-6.

[24] Sharma V, Singh P, Pandey AK, Dhawan A. Induction of oxidative stress, DNA damage and apoptosis in mouse liver after sub-acute oral exposure to zinc oxide nanoparticles. Mutat Res 2012; 745(1-2): 84-91. [http://dx.doi.org/10.1016/j.mrgentox.2011.12.009] [PMID: 22198329]

[25] Atef HA, Mansour MK, Ibrahim EM, et al. Efficacy of zinc oxide nanoparticles and curcumin in amelioration the toxic effects in aflatoxicated rabbits. Int J Curr Microbiol Appl Sci 2016; 5(12): 795-818. [http://dx.doi.org/10.20546/ijcmas.2016.512.090]

[26] Richard JL. Some major mycotoxins and their mycotoxicoses--an overview. Int J Food Microbiol 2007; 119(1-2): 3-10. [http://dx.doi.org/10.1016/j.ijfoodmicro.2007.07.019] [PMID: 17719115]

[27] Pasquet J, Chevalier Y, Couval E, et al. Antimicrobial activity of zinc oxide particles on five micro-organisms of the Challenge Tests related to their physicochemical properties. Int J Pharm 2014; 460(1-2): 92-100. [http://dx.doi.org/10.1016/j.ijpharm.2013.10.031] [PMID: 24211859]

[28] Applerot BG, Lipovsky A, Dror R, et al. Enhanced antibacterial activity of nanocrystalline ZnO due to increased ROS mediated cell injury. Adv Funct Mater 2009; 52900: 842-52. [http://dx.doi.org/10.1002/adfm.200801081]

[29] Mielcarz-Skalska L, Smolińska B. Zinc and nano-ZnO - influence on living organisms. Biotechnol Food Sci 2017; 81(2): 93-102.

[30] Cross SE, Innes B, Roberts MS, Tsuzuki T, Robertson TA, McCormick P. Human skin penetration of sunscreen nanoparticles: In-vitro assessment of a novel micronized zinc oxide formulation. Skin Pharmacol Physiol 2007; 20(3): 148-54. [http://dx.doi.org/10.1159/000098701] [PMID: 17230054]

[31] Filipe P, Silva JN, Silva R, et al. Stratum corneum is an effective barrier to TiO2 and ZnO nanoparticle percutaneous absorption. Skin Pharmacol Physiol 2009; 22(5): 266-75. [http://dx.doi.org/10.1159/000235554] [PMID: 19690452]

[32] Osmond MJ, McCall MJ. Zinc oxide nanoparticles in modern sunscreens: An analysis of potential exposure and hazard. Nanotoxicology 2010; 4(1): 15-41.

[http://dx.doi.org/10.3109/17435390903502028] [PMID: 20795900]

[33] Roy R, Kumar S, Verma AK, et al. Zinc oxide nanoparticles provide an adjuvant effect to ovalbumin via a Th2 response in Balb/c mice. Int Immunol 2014; 26(3): 159-72. [http://dx.doi.org/10.1093/intimm/dxt053] [PMID: 24225181]

[34] Condello M, De Berardis B, Ammendolia MG, et al. ZnO nanoparticle tracking from uptake to genotoxic damage in human colon carcinoma cells. Toxicol In Vitro 2016; 35: 169-79.

[http://dx.doi.org/10.1016/j.tiv.2016.06.005] [PMID: 27317967]

[35] Cho WS, Duffin R, Howie SE, et al. Progressive severe lung injury by zinc oxide nanoparticles; the role of Zn2+ dissolution inside lysosomes. Part Fibre Toxicol 2011; 8: 27. [http://dx.doi.org/10.1186/1743-8977-8-27] [PMID: 21896169]

[36] Sahu D, Kannan GM, Vijayaraghavan R, Anand T, Khanum F. Nanosized zinc oxide induces toxicity in human lung cells. ISRN Toxicol 2013; 2013: 316075 . [http://dx.doi.org/10.1155/2013/316075] [PMID: 23997968]

[37] Han D, Tian Y, Zhang T, Ren G, Yang Z. Nano-zinc oxide damages spatial cognition capability via over-enhanced long-term potentiation in hippocampus of Wistar rats. Int J Nanomedicine 2011; 6: 1453-61.

[PMID: 21796247]

[38] Elshama SS, Osman HEH, El-Kenawy AE. Histopathological study of zinc oxide nanoparticle-induced neurotoxicity in rats. Curr Top Toxicol J 2017; 13: 95-103.

[39] Li CH, Shen CC, Cheng YW, et al. Organ biodistribution, clearance, and genotoxicity of orally administered zinc oxide nanoparticles in mice. Nanotoxicology 2012; 6(7): 746-56.

[http://dx.doi.org/10.3109/17435390.2011.620717] [PMID: 21950449]

[40] Fazilati M. Investigation toxicity properties of zinc oxide nanoparticles on liver enzymes in male rat. Eur J Exp Biol 2013; 3(1): 97-103.

[41] Soheili S, Moradhaseli S, Shokouhian A, Ghorbani M. Histopathological effects of ZnO nanoparticles on liver and heart tissues in wistar rats. Adv Biores 2013; 4(2): 83-8.

[42] Esmaeillou M, Moharamnejad M, Hsankhani R, Tehrani AA, Maadi H. Toxicity of ZnO nanoparticles in healthy adult mice. Environ Toxicol Pharmacol 2013; 35(1): 67-71. [http://dx.doi.org/10.1016/j.etap.2012.11.003] [PMID: 23262039]

[43] Ko JW, Hong ET, Lee IC, et al. Evaluation of 2-week repeated oral dose toxicity of 100 nm zinc oxide nanoparticles in rats. Lab Anim Res 2015; 31(3): 139-47.

[http://dx.doi.org/10.5625/lar.2015.31.3.139] [PMID: 26472967]

[44] Seok SH, Cho WS, Park JS, et al. Rat pancreatitis produced by 13-week administration of zinc oxide nanoparticles: Biopersistence of nanoparticles and possible solutions. J Appl Toxicol 2013; 33(10): 1089-96. [http://dx.doi.org/10.1002/jat.2862] [PMID: 23408656] 
[45] Kim YR, Park JI, Lee EJ, et al. Toxicity of $100 \mathrm{~nm}$ zinc oxide nanoparticles: A report of 90-day repeated oral administration in Sprague Dawley rats. Int J Nanomedicine 2014; 9(2)(Suppl. 2): 109-26. [PMID: 25565830]

[46] Elshama SS, Salem RR, Osman HEH, El-Kenawy AE. Toxic effect of sub-chronic use of zinc oxide nanoparticles on the lymphatic system of adult albino rats. Curr Top Toxicol J 2017; 13: 127-37.

[47] Reza EH, Mohammad F, Leila S, Vahid YB, Somayeh B, Esmail A. Investigation the Zinc Oxide Nanoparticle's Effect on Sex Hormones and Cholesterol in Rat. Int Res J Biol Sci 2013; 2(8): 54-8.

[48] Hong JS, Park MK, Kim MS, et al. Prenatal development toxicity study of zinc oxide nanoparticles in rats. Int J Nanomedicine 2014; 9(2)(Suppl. 2): 159-71. [PMID: 25565834]

\section{(C) 2018 Elshama et al.}

This is an open access article distributed under the terms of the Creative Commons Attribution 4.0 International Public License (CC-BY 4.0), a copy of which is available at: https://creativecommons.org/licenses/by/4.0/legalcode. This license permits unrestricted use, distribution, and reproduction in any medium, provided the original author and source are credited. 